\title{
HEREDITY, STRESS AND BLOOD PRESSURE, A FAMILY SET APPROACH: THE DETROIT PROJECT REVISITED
}

\author{
P. P. Moll,${ }^{1.2}$ E. Harburg,,${ }^{1.3}$ T. L. Burns, ${ }^{4}$ M. A. SChORK ${ }^{4}$ and F. OzgOren ${ }^{1}$ \\ Departments of ${ }^{1}$ Epidemiology, ${ }^{2}$ Human Genetics, ${ }^{3}$ Psychology and ${ }^{4}$ Biostatistics. \\ University of Michigan, Ann Arbor, MI 48109, U.S.A.
}

(Received in revised form 1 November 1982)

\begin{abstract}
Earlier conclusions from the Detroit Project utilizing an innovative "family sets" approach indicated that unspecified environmental factors, rather than genes, are the main determinants of blood pressure variation in blacks and whites. We report new estimates of the fraction of variation in blood pressure associated with genetic differences among individuals obtained under two methodologies: the method originally proposed for family sets and a maximum likelilıood method. The family sets estimates of heritability were significant for systolic and diastolic blood pressure in both blacks and whites. Estimates for both the likelihood analysis and family sets method are within the range of estimates reported in other studies. In the present study all sets collected were included, the sets were stratified only by race and a different estimate of variance for the family sets estimate of heritability was used. The discrepancies between results presented here and the original study are attributed to these three factors.
\end{abstract}

\section{INTRODUTTION}

BLOOD pressure has long been recognized as a unimodally distributed quantitative trait that is an important risk factor for cardiovascular disease. The variability of blood pressure in a population reflects biological diversity among individuals, different environmental experiences (both shared and individual specific), and measurement error. Differences in age, sex and weight also contribute to blood pressure variation. Studies have indicated that clustering of hypertension occurs in families [1]. Familial aggregation of blood pressure levels has been found in studies conducted in populations with very diverse geographic and cultural environments [2] and it is of interest to know whether shared environments and/or shared genes contribute significantly to the familial aggregation of blood pressure.

Various estimates of the fraction of phenotypic variation in blood pressure associated with genetic differences among individuals have been reported [3-8]. The estimates, obtained using different models, different statistical procedures, various genetic relationships among individuals, and diversified cultural backgrounds, are summarized in Table 1. In every case the genetic variability associated with either diastolic or systolic blood pressure variation was significant. The one exception to this general finding was the study by Harburg et al. [9] designed to separate genetic from environmental effects on blood pressure in blacks and whites living in Detroit, Michigan. In contrast to other recent studies, the results from Detroit did not indicate that a significant fraction of blood pressure variation is associated with genetic variability. The conclusion, instead, was that unspecified environmental factors are the main determinants of blood pressure variation in both blacks and whites in this particular study.

Supported by: Grant \#78-942, American Heart Association; Grant \#HE13329, National Heart and Lung Instilute; Michigan Heart Association

National Heart, Lung and Blood Institute Cardiovascular Training Grant \#5 T32 HL07082 (T.L.B.). 
TABle 1. Proportion OF VARIATION iN BLOOD PRESSURE ASSOClated WITH GENF TIC VARIABILITY IX ADULTS

\begin{tabular}{lcc}
\hline \multicolumn{1}{c}{ Sample } & \multicolumn{2}{c}{ Estimates \pm SE (if reported) } \\
\cline { 2 - 3 } & $\begin{array}{c}\text { Systolic } \\
\text { blood pressure }\end{array}$ & $\begin{array}{c}\text { Diastolic } \\
\text { blood pressure }\end{array}$ \\
\hline $\begin{array}{l}\text { Japanese-American } \\
\text { nuclear families in Hawaii } \\
\text { (Morton et al.. 1980) }\end{array}$ & $0.24 \pm 0.04$ & $0.19 \pm 0.04$ \\
$\begin{array}{l}\text { U.S. male twins aged 42 56 } \\
\text { (Borhani et al., 1976) }\end{array}$ & 0.82 & 0.64 \\
$\begin{array}{l}\text { Polynesian nuclear families } \\
\text { in the Tokelau Islands } \\
\text { (Ward et al.. 1979) }\end{array}$ & 0.28 & 0.25 \\
$\begin{array}{l}\text { Montreal families with all } \\
\text { natural children. all adopted } \\
\text { children and both natural } \\
\text { and adopted children } \\
\text { (Annest et al., 1979) }\end{array}$ & $0.34 \pm 0.08$ & $0.30 \pm 0.09$ \\
$\begin{array}{l}\text { Northern Brazil nuclear } \\
\text { families } \\
\text { (Krieger et al., 1980) }\end{array}$ & & \\
$\begin{array}{l}\text { Families of monozygotic } \\
\text { female twins } \\
\text { (Ewell et al., 1978) }\end{array}$ & $0.14 \pm 0.04$ & $0.34 \pm 0.03$ \\
\hline
\end{tabular}

The data for the Detroit Project were collected using an innovative "family sets" design consisting of 5 persons of similar age: an index subject, his or her spouse, full sibling, first cousin, and an unrelated person of the same sex residing in the same neighborhood as the index. A general method was developed to estimate the genetic variation associated with variability in a quantitative trait based upon the family sets design [10].

Since the conclusion of the Detroit Project, a likelihood model originally proposed by Elston and Stewart [11] and extended by Lange et al. [12] has been applied to quantitative data on dermal ridge counts, total cholesterol and blood pressure $[13,14,5]$. The model combines phenotypic, genealogical and environmental information to estimatc both genetic and environmental components of variance from pedigrees. In this paper we fit a model which explains the aggregation of blood pressure measurements between different members of a family set in terms of genes shared by related individuals and environments shared by both related and unrelated individuals of the set. The maximum likelihood model developed by Lange et al. [12] and extended by Moll et al. [14] for the estimation of variance components is utilized. Estimates of genetic variability obtained by this alternative analytical approach are then compared to the estimates obtained by the method originally proposed for family sets [10]. This reanalysis of the Detroit data supports the hypotheses that genetic variability and variability in environments are associated with variability in blood pressure in blacks and whites in Detroit.

\section{SAM PLE}

The first phase of the Detroit Project consisted of the identification of specific residence areas in Detroit that varied in extremes of high stressor and low stressor conditions, relative to the city as a whole [15]. Rates that reflect economic deprivation, residential instability, family instability, crime, and population density were computed for each of 382 Detroit census tracts using data collected in 1964. It was assumed that such combined rates, at their endpoints, indicated social environments which varied objectively in chronic exposure to stressor events. The rates per census tract were factor analyzed and the 382 tracts were each assigned factor scores for the two emergent factors: socioeconomic status (SES) and instability [16]. Four stress areas in the city were chosen 
for being in the extreme quartiles of the factor scores. For example, high SES and low instability defined a low stress area and the converse defined a high stress area. Two stress areas (one high and one low) were defined for blacks and two for whites. A stress area designation for family set members living outside the city was determined using a separate coding system based on data from the 1965 Transportation and Land Use Study special $4 \%$ sample of the Standard Metropolitan Statistical Area. Crime rate was not readily available for these township areas, though marital status was. The classification of "high" and "low" stress area used in this analysis is weighted more in terms of SES mcasures than instability measures for a very small portion (about $3 \%$ ) of the total sample who lived outside the city of Detroit.

Sampling of index persons was initiated within each of the four primary stress areas. The index cases were individuals who: (1) resided in these areas; (2) were of a given race; (3) were between 25 and 59 years of age; (4) lived with a spouse; and (5) had siblings and first cousins in the Metropolitan arca. This process was carried out in two stages. In Stage I, a door-to-door census was taken in each of the four stress areas to classify potential sample members. The census refusal rate was about $2-3 \%$ in each area. Next, each person classified as having the five sample traits already described (potential sample member) was visited by a trained interviewer. This verification interview rechecked the inclusion criteria of the person and data on relatives. If verified, the person's cooperation was requested and an interview by a nurse was arranged. In Stage II, trained nurses of the same race as the respondent were randomly assigned to interview the randomly selected persons residing in high and low stress areas, changing the area each week for each nurse. The refusal rate was similar across all areas and averaged about $4 \%$.

Briefly, the family sets in this study consisted of an index (I), his or her full sibling (Sib) of either sex closest in age to the index, his or her first cousin (FC) of either sex closest in age to the index, his or her spouse (Sp), and an unrelated person (Un) matched to I for race, age, sex, place of residence, marital status, and having sibs and cousins in the Detroit area. The sib and cousin in a family set provide genetic information, while the spouse and unrelated person serve as "controls" for certain environmental factors [9]. The spouse serves as an "immediate environment" control for the index. They share the same dwelling unit and other factors such as diet and water. The unrelated person serves as a control for other environmental factors outside the dwelling unit but within the same urban, socio-environmental area. Age effects on the trait of interest and temporal trends are minimized by choosing all members of the set from a limited age interval. The final study sample consisted of 229 black sets with 118 male index cases and 111 female index cases and 232 white family sets with 113 male index cases and 119 female index cases. Approximately one-third of all sets had every member residing in a similarly defined stress area.

The variables used in these analyses were systolic and diastolic blood pressures (SBP and DBP), age, sex, race, percent overweight and classification of residence as either in a low or high stress area. SBP was the average of the first three systolic readings taken at $10 \mathrm{~min}$ intervals during the first half hour of the interview, and DBP was the average of the first three diastolic (fifth phase) readings. Percent overweight was computed by comparing reported weight with Metropolitan Life Tables [17] for weight by sex and height. These data have been extensively described elsewhere $[2,9,10,18-21]$.

\section{MODEL}

The multifactorial determination of an individual's phenotype $(P)$ can be expressed as the linear combination: $P=G \mid E$, where $P$, the deviation of blood pressurc from its mean, is partitioned into two components: $G$, the deviation due to an individual's genotype. and $E$, is the deviation due to environmental experiences. The total phenotypic variance, $\sigma_{P}^{2}$, is the sum of $\sigma_{f i}^{2}$ and $\sigma_{E}^{2}$. The genetic component of the multifactorial determination of normal blood pressure variability is parameterized according to Fisher's polygene model [22] which assumes Hardy-Weinberg equilibrium, linkage equilibrium, no dominance or epistasis and no genotype by environment interaction or 
correlation. Therefore, $\sigma_{G}^{2}=\sigma_{A}^{2}$, the additive genetic variance. In addition, we assumed that there was no assortative mating for the genes which contribute to $\sigma_{G}^{2}$.

We considered an environmental component of variability attributable to effects that could be shared by various members of the family set, $\sigma_{C E}^{2}$, and a residual component which includes measurement error as well as environmental effects special to the individual, $\sigma_{R}^{2}$. Total phenotypic variance may be written:

$$
\sigma_{P}^{2}=\sigma_{A}^{2}+\sigma_{C E}^{2}+\sigma_{R}^{2}
$$

Three types of shared environments may be defincd for these family scts. The first, $\sigma_{C E \text {-House }}^{2}$, defines effects each individual experiences that are associated with the household in which he lives. Since the I and Sp were the only members of the set residing in the same household at the time of the study, no other members of the set share the same household effect. In cross-sectional studies such as this, with no information available on the length of cohabitation or marriagc betwecn spouscs, the possible cffect of sharing a household on spouse resemblance cannot be distinguished from assortative mating of phenotypes [23]. The second variance component, $\sigma_{C E-A r e: 1}^{2}$, defines environmental effects associated with the area in which an individual lives. Members of the family set who reside in a similar stress area share this effect. The last component defines effects associated with variability in a combination of demographic factors (age, sex, marital status, and family structure). Because of the factors used to match the I and Un in this particular family sets design, we assume that only these two individuals share this component which we denote $\sigma_{C E-(1-(\mathrm{ln})}^{2}$.

Incorporating these environmental effects into the linear model, the phenotypic variance for each family set member becomes

$$
\sigma_{A}^{2}+\left\{\sigma_{C E-\mathrm{H}(\mathrm{uLC} \mathrm{C}}^{2}+\sigma_{C E-\mathrm{Area}}^{2}+\sigma_{C E-(\mathrm{I}-\mathrm{ln})}^{2}\right\}+\sigma_{R}^{2}
$$

The expected covariance between any two set members $i$ and $j$ for the trait when the model is true is:

$$
\operatorname{COV}(i, j)=2 \phi_{i j} \sigma_{A}^{2}+R_{i j} \sigma_{C E-\mathrm{H} \text { ous }}^{2}+S_{i j} \sigma_{C E-\mathrm{ArEa}}^{2}+T_{i j} \sigma_{C E-(1-\mathrm{in})}^{2}+\mathrm{I}_{i j} \sigma_{R}^{2}
$$

The kinship coefficient, $\phi_{i j}$, for individuals $i$ and $j$ is the probability that an allele chosen at random from $i$ is identical by descent with an allele at the same locus chosen at random from $j . \phi_{i j}$ is $1 / 4$ for siblings and $1 / 16$ for first cousins and $1 / 2$ if $i=j . R_{i j}, S_{i j}, T_{i j}$ and $\mathrm{I}_{i j}$ are each 1.0 if $i=j$. If $i \neq j, \mathrm{I}_{i j}$ is zero. If $i \neq j, R_{i j}$ is 1.0 if $i$ and $j$ reside in the same house (i.e. are spouses), $S_{i j}$ is 1.0 if $i$ and $j$ both reside in the same stress area and $T_{i j}$ is 1.0 if $i$ and $j$ have been matched for race, age, sex, marital status and family structure. Otherwise, these three coefficients are zero.

Two different statistical treatments of the data considered were variance components estimation using maximum likelihood methods and heritability estimation using a family sets statistic. The likelihood of the model given the data is obtained by assuming a multivariate normal distribution for the trait among members of the family set. Justification for this assumption is given by Lange [24]. Under this assumption, the likelihood $(L)$ expressed as the natural log of the multivariate normal can be written as:

$$
L=-(1 / 2) \ln |\mathbf{C O V}|-(1 / 2)(\mathbf{X}-\boldsymbol{\mu})^{\prime} \mathbf{C O V}^{-1}(\mathbf{X}-\boldsymbol{\mu})
$$

[25]. The elements of the COV matrix are functions of the five variance components given in equation 3 and the genealogical, marital and residence information. Blood pressure values for the members of a family set are represented by the vector $\mathbf{X}$, while $\boldsymbol{\mu}$ is the mean vector for all individuals in this study of the same race. Estimates of the mean and five variance components are taken to be those values which maximize $L$. Detailed descriptions of Fisher's scoring algorithm, and the iteration procedure used to obtain these maximum likelihood estimates and their standard errors are given elsewhere $[12,14]$. Hypothesis testing is based on the likelihood ratio criterion where -2 times the difference in $\ln$ likelihoods between a reduced model with one or more components set 
equal to zero and a complete model, approximates a chi-square distribution when the reduced hypothesis is true, with degrees of freedom equal to the difference in the number of independent variables in the two models. While the likelihood ratio method provides no way of testing the goodness of fit of the data to the best fitting model, it does allow the comparison of different reduced models to a complete model.

One of the statistical models developed for data from a family sets design assumes that the effects of alleles are only additive. The estimator for $\sigma_{A}^{2} / \sigma_{P}^{2}$ which is referred to as the heritability $[10]$ and denoted by $h^{2}$, is

$$
(4 / 3)\left\{S^{2}\left(X_{1}-X_{\text {ICC }}\right)-S^{2}\left(X_{\mathrm{I}}-X_{\mathrm{Sib}}\right)\right\} / S^{2}\left(X_{A}\right)
$$

where $S^{2}\left(X_{1}-X_{\mathrm{Sib}}\right)$ and $S^{2}\left(X_{1}-X_{\mathrm{rC}}\right)$ are the variances of the differences in values between the I and Sib and the I and FC, respectively. $S^{2}\left(X_{A}\right)$ represents the average variance in the trait for the I, Sib, FC and Un. The contributions of shared environmental experiences among index, sibling and cousin to the cstimate of additive genetic variance are expected to be minimized under this model [10]. The variance for the estimate of $h^{2}$ is

$$
\left\{64 / 9-(49 / 12)\left(h^{2}\right)+(14 / 9)\left[\left(h^{2}\right)^{2}\right]\right\} / N
$$

where $N$ is the number of family sets [26]. This estimate is used to test the hypothesis that $h^{2}$ is equal to zero.

\section{ADJUSTMENT OF THE DATA}

In the previous analysis of these data, age, sex, race, body size and area of residence were found to be associated with blood pressure levels [20]. We chose to eliminate these sources of variability before estimation of variance components and heritability. The familial aggregation for both age and body size in these data that is confounded with aggregation for blood pressure was removed. The adjustment for area of residence reduces the effect of unequal representation of the various stress areas within and between family sets in each race. Failure to adjust for this effect might bias the estimates of both genetic and environmental components. Within each race, sex and stress area group, multiple linear regression was used to adjust SBP and DBP separately for the effects of age and percent overweight. The residuals within each of the eight groups were then standardized to remove the significant heterogeneity in variance. Finally, to meet the distributional assumptions of the model, standardized residuals were normalized within each race group using the inverse rank normal transformation which assigns to each observation that standard normal deviate having the same accumulated probability the observation has, based on the empiric distribution of that variable. After these adjustments, neither SBP nor DBP for any of the five groups of family set member types within races differed significantly from a normal distribution with a mean of zero and standard deviation of 1.0. While normality is an assumption of the model, results from previous studies of cholesterol are similar with both normal and non-normal distributions [14].

\section{RESULTS}

The proportion of variation in SBP and DBP accounted for by variability in age and percent overweight in each race, sex and stress group was highly significant and is reported in Table 2, along with means and standard deviations of the original SBP, DBP measures, age and percent overweight. While not shown in the table, the proportion of variation accounted for by age was slightly higher than that accounted for by percent overweight in SBP when the two independent variables were considered separately; while in DBP, age accounted for slightly less variation. There was evidence for significant familial aggregation in the adjusted data. We rejected at the $5 \%$ level of significance the hypothesis that the within sibship mean levels of blood pressure were equal among the family sets in both blacks and whites for DBP and whites only for SBP. We also rejected 


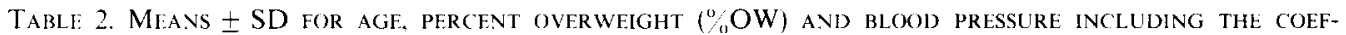
FICIINT OF MULTIPLE DETERMINATION $\left(R^{2}\right)$ FOR THE MULTIPLE REGRESSION OF SBP AND DBP ON AGE AND $\% \mathrm{OW}$

\begin{tabular}{lccccccc}
\hline \multicolumn{1}{c}{ Strata } & $N$ & Age & $\%$ OW & SBP & $R^{2}$ & DBP & $R^{2}$ \\
\hline $\begin{array}{l}\text { Black males } \\
\text { High stress area }\end{array}$ & 275 & $41.6 \pm 9.1$ & $13.6 \pm 16.3$ & $132 \pm 20.4$ & $0.110^{*}$ & $85.6 \pm 13.1$ & $0.066^{*}$ \\
$\quad$ Low stress area & 293 & $40.4 \pm 7.9$ & $14.5 \pm 15.4$ & $129 \pm 20.5$ & $0.196^{*}$ & $81.4 \pm 12.1$ & $0.215^{*}$ \\
Black females & & & & & & & \\
$\quad$ High stress area & 288 & $40.3 \pm 8.4$ & $21.1 \pm 24.5$ & $128 \pm 20.6$ & $0.176^{*}$ & $82.6 \pm 13.1$ & $0.091^{*}$ \\
$\quad$ Low stress area & 289 & $39.2 \pm 7.3$ & $14.4 \pm 20.9$ & $124 \pm 20.2$ & $0.177^{*}$ & $80.7 \pm 12.7$ & $0.177^{*}$ \\
White males & & & & & & & \\
$\quad$ High stress area & 271 & $40.8 \pm 8.4$ & $13.1 \pm 16.8$ & $128 \pm 16.3$ & $0.125^{*}$ & $82.5 \pm 10.8$ & $0.108^{*}$ \\
$\quad$ Low stress area & 318 & $43.9 \pm 7.9$ & $14.7 \pm 15.5$ & $129 \pm 15.7$ & $0.114^{*}$ & $82.7 \pm 10.7$ & $0.079^{*}$ \\
White females & & & & & & & \\
$\quad$ High stress area & 275 & $40.8 \pm 8.7$ & $13.7 \pm 22.8$ & $121 \pm 19.9$ & $0.258^{*}$ & $76.8 \pm 11.6$ & $0.205^{*}$ \\
Low stress area & 296 & $42.4 \pm 8.0$ & $12.0 \pm 21.5$ & $120 \pm 18.5$ & $0.221^{*}$ & $76.7 \pm 10.9$ & $0.197^{*}$ \\
\hline
\end{tabular}

$*_{p}<0.001$.

the hypothesis that the mean level of SBP between the index and spouse was equal for the white family sets.

The maximum likelihood estimates of the variance components, their standard errors and $\ln$ likelihoods are given in Table 3 for SBP and Table 4 for DBP. Estimates are given for both the complete model, which assumes one genetic and threc common environmental components, and for several reduced models. Each reduced model represents the null hypothesis that the true value of any parameter omitted is zero. Reduced Model A assumes a genetic and residual environmental component for variability and omits the three common environmental components. Reduced Model B assumes no additive genctic component of variability. In addition to reduced Models A and B, there are 12 other reduced models that could be considered. The Model $\mathrm{C}$ in Tables 3 and 4 represents the choice among all 14 reduced models that has the fewest components and explains the

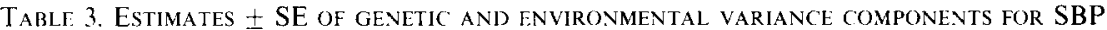

\begin{tabular}{|c|c|c|c|c|}
\hline \multirow[b]{2}{*}{ Components } & \multirow[b]{2}{*}{ Complete model } & \multicolumn{3}{|c|}{ Reduced models } \\
\hline & & $A$ & $\mathrm{~B}$ & $\mathrm{C}$ \\
\hline \multicolumn{5}{|l|}{ Black sets: } \\
\hline Additive genetic & $0.130 \pm 0.13$ & $0.165 \pm 0.12$ & & \\
\hline \multicolumn{5}{|l|}{$\begin{array}{l}\text { Common } \\
\text { environments }\end{array}$} \\
\hline Area & $0.032 \pm 0.03$ & & $0.043 \pm 0.03$ & \\
\hline House & $0.001 \pm 0.07$ & & $0.001 \pm 0.07$ & \\
\hline l-Un & $0.019 \pm 0.07$ & & $0.001 \pm 0.07$ & \\
\hline Residual & $0.833 \pm 0.17$ & $0.824 \pm 0.13$ & $0.986 \pm 0.11$ & $0.989 \pm 0.01$ \\
\hline $\ln L$ & -564.72 & -565.35 & -565.15 & -566.35 \\
\hline $\begin{array}{l}z^{2} \text { complete vs } \\
\text { reduced }(d f)\end{array}$ & & $1.26(3)$ & $0.86(1)$ & $3.26(4)$ \\
\hline \multicolumn{5}{|l|}{ White sets: } \\
\hline Additive genetic & $0.320 \pm 0.13$ & $0.256 \pm 0.12$ & & $0.253 \pm 0.12$ \\
\hline \multicolumn{5}{|l|}{$\begin{array}{l}\text { Common } \\
\text { environments }\end{array}$} \\
\hline Area & $0.001 \pm 0.03$ & & $0.001 \pm 0.03$ & \\
\hline House & $0.195 \pm 0.07$ & & $0.180 \pm 0.07$ & $0.127 \pm 0.06$ \\
\hline I-Un & $0.090 \pm 0.07$ & & $0.084 \pm 0.07$ & \\
\hline Residual & $0.449 \pm 0.15$ & $0.736 \pm 0.12$ & $0.771 \pm 0.09$ & $0.610 \pm 0.13$ \\
\hline $\ln L$ & -568.24 & -571.71 & -571.48 & -570.48 \\
\hline $\begin{array}{l}\gamma^{2} \text { complete vs } \\
\text { reduced }(d f)\end{array}$ & & $6.94(3)^{*}$ & $6.48(1)^{* *}$ & $4.48(2)$ \\
\hline
\end{tabular}

$* 0.05<p<0.10 ; * * p<0.05$. 
TABle 4. Estimates \pm SE of Genetic and ENVIRONMENTAL VARIANCE COMPONENTS FOR DBP

\begin{tabular}{|c|c|c|c|c|}
\hline \multirow[b]{2}{*}{ Components } & \multirow[b]{2}{*}{ Complete model } & \multicolumn{3}{|c|}{ Reduced models } \\
\hline & & A & B & $\mathrm{C}$ \\
\hline \multicolumn{5}{|l|}{ Black sets: } \\
\hline Additive genetic & $0.285 \pm 0.13$ & $0.373 \pm 0.12$ & & $0.373 \pm 0.12$ \\
\hline \multicolumn{5}{|l|}{$\begin{array}{l}\text { Common } \\
\text { environments }\end{array}$} \\
\hline Area & $0.068 \pm 0.03$ & & $0.090 \pm 0.03$ & \\
\hline House & $0.010 \pm 0.07$ & & $0.001 \pm 0.07$ & \\
\hline I-Un & $0.010 \pm 0.07$ & & $0.001 \pm 0.07$ & \\
\hline Residual & $0.579 \pm 0.14$ & $0.618 \pm 0.12$ & $0.901 \pm 0.11$ & $0.618 \pm 0.12$ \\
\hline $\ln L$ & -559.47 & -562.45 & -561.23 & -562.45 \\
\hline $\begin{array}{l}\chi^{2} \text { complete vs } \\
\text { reduced }(d f)\end{array}$ & & $5.96(3)$ & $3.56(1)^{*}$ & $5.96(3)$ \\
\hline \multicolumn{5}{|l|}{ White sets: } \\
\hline Additive genetic & $0.230 \pm 0.13$ & $0.219 \pm 0.12$ & & \\
\hline \multicolumn{5}{|l|}{$\begin{array}{l}\text { Common } \\
\text { environments }\end{array}$} \\
\hline Area & $0.001 \pm 0.03$ & & $0.001 \pm 0.09$ & \\
\hline House & $0.247 \pm 0.07$ & & $0.244 \pm 0.07$ & $0.207 \pm 0.06$ \\
\hline I-Un & $0.079 \pm 0.07$ & & $0.082 \pm 0.07$ & \\
\hline Residual & $0.467 \pm 0.15$ & $0.769 \pm 0.12$ & $0.684 \pm 0.09$ & $0.784 \pm 0.07$ \\
\hline $\ln L$ & -567.66 & -572.22 & -569.50 & -570.03 \\
\hline $\begin{array}{l}\chi^{2} \text { complete vs } \\
\text { reduced }(d f)\end{array}$ & & $9.12(3)^{* *}$ & $3.68(1)^{*}$ & $4.74(3)$ \\
\hline
\end{tabular}

${ }^{*} 0.05<p<0.10 ;{ }^{* *} p<0.05$.

data as well as the complete model. Under Model C, any omitted parameter does not contribute significantly to the explanation of the data. Model $\mathrm{C}$ was not fixed to have the same components for SBP and DBP in blacks and whites. Chi-square values obtained from contrasts of the ln likelihoods of reduced Models A, B and C with the complete model are also given in Tables 3 and 4 .

For the black family sets, we reject the hypotheses that either shared genes or shared environments, as defined by this model, contribute significantly to the explanation of variation in SBP. The In likelihood of the complete model is not significantly higher than the In likelihoods for reduced Models A, B or C as judged by the chi-square values. For SBP in whites, the chi-squares obtained from all contrasts with the complete model suggest that the genetic and some of the common environmental components of variance are non-zero. Model $\mathrm{C}$ with additive genetic and shared household components is the reduced model that fits the data as well as the complete model. A reduced model, not presented in Table 3, with all components except the residual component set equal to zero was rejected as explaining the data.

For DBP in blacks, the model with additive effects of genes and the residual component contributing significantly to familial aggregation of DBP was the best fitting reduced model. Therefore Model A and Model C are the same model for these sets. None of the shared environmental components, as defined in this model, contribute significantly. In contrast, for DBP among whites, the reduced Model $\mathrm{C}$ with common household and residual components is judged, statistically, to explain the data about as well as the complete model based on the chi-square value. For both blacks and whites, the hypothesis that all components except the residual component are zero was rejected.

In summary, the data from white family sets support the hypothesis that additive polygenes and variability in environmental experiences shared by spouses living in the same household are associated with variability in SBP, and that only the household shared environment is associated with variability in DBP. The data from black family sets support the hypothesis that variability in additive polygenes is associated with 
TABLE 5. HeRITABILITY ESTIMATES Based ON THE FAMil. Y SETS METHOD*

\begin{tabular}{lcrrr}
\hline \multirow{2}{*}{\multicolumn{1}{c}{ Slatistic }} & \multicolumn{2}{c}{ Systolic blood pressure } & \multicolumn{2}{c}{ Diastolic blood pressure } \\
\cline { 2 - 5 } \multicolumn{1}{c}{ Blacks } & Whites & \multicolumn{1}{c}{ Blacks } & Whites \\
\hline Number of sets & 229 & 232 & 229 & 232 \\
$S_{\mathrm{I}}^{2}$ & 0.974 & 0.894 & 0.933 & 0.890 \\
$S_{\mathrm{Sib}}^{2}$ & 0.990 & 1.129 & 0.916 & 1.184 \\
$S_{\mathrm{FC}}^{2}$ & 0.960 & 1.159 & 1.001 & 1.063 \\
$S_{\mathrm{Un}}^{2}$ & 0.997 & 0.937 & 0.925 & 0.997 \\
Average & 0.980 & 1.030 & 0.944 & 1.034 \\
$S^{2}\left(X_{1}-X_{\mathrm{Sib}}\right)$ & 1.789 & 1.701 & 1.500 & 1.772 \\
$S^{2}\left(X_{1}-X_{\mathrm{FC}}\right)$ & 2.049 & 2.033 & 1.874 & 2.064 \\
$d$ & 0.260 & 0.332 & 0.374 & 0.292 \\
$h^{2} \pm \mathrm{SE}$ & $0.354 \pm 0.160$ & $0.430 \pm 0.156$ & $0.528 \pm 0.153$ & $0.377 \pm 0.158$ \\
\hline
\end{tabular}

*Statistics are defined in text.

variability in DBP but that variability in SBP is not associated with any of the shared components defined in these models.

The estimates of heritability based on the family sets estimator are given in Table 5 using notation that is similar to that presented in Tables 3 through 6 in Chakraborty et al. [10]. $S_{Y}^{2}$ is the variance for family set members where $Y$ is the I, Sib, FC or Un. The difference between the two variances, $S^{2}\left(X_{1}-X_{\mathrm{FC}}\right)$ and $S^{2}\left(X_{1}-X_{\mathrm{Sib}}\right)$, is "d" in Table 5. The estimates of $h^{2}$ and their standard errors were computed using equations 5 and 6 above. All of the estimates of $h^{2}$ are significantly greater than zero and rank among themselves from highest to lowest similarly to the estimates of the additive components (Model A) in Tables 3 and 4. The estimate of $h^{2}$ for DBP in blacks is highest while the estimate of $h^{2}$ for SBP in blacks is the lowest. Since the data have been standardized within races with a mean of zero and variance of 1.0, and both models have the assumption of only additive alleles, for these data $h^{2}$ and $\sigma_{A}^{2}$ should be estimates of the same source of variability. For SBP and DBP in both blacks and whites the estimates from the

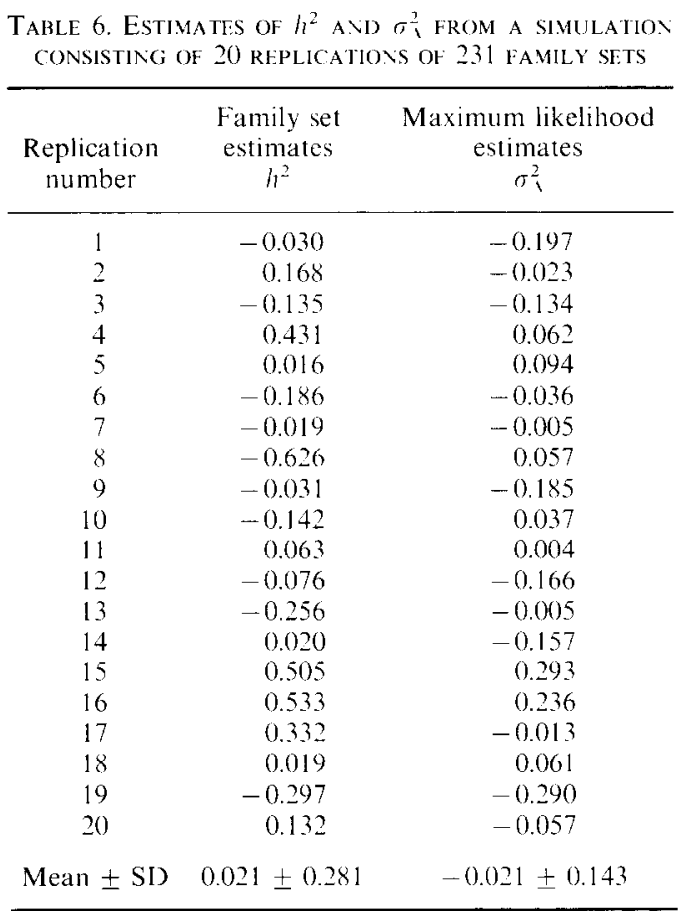


family sets estimator are higher than the corresponding estimates from the variance components model. In summary, the family sets estimators support the hypothesis that genetic differences among individuals are associated with variability in SBP and DBP in both blacks and whites.

In addition to the analyses reported above, we performed a small simulation experiment to directly compare the maximum likelihood method to the family sets method of estimation when the true heritability was known. Standard normal deviates were generated for each member of 231 family sets. The results of analyzing 20 replications of this experinent using the likelihoud and fanily sets methods are in Table 6. Our expectation was that the estimates of both $\sigma_{A}^{2}$ and $h^{2}$ would be 0.0 . The mean of the estimates of $h^{2}$ from the family sets method was $0.021 \pm 0.281$ while the mean of the estimates from the likelihood approach (assuming Model A described earlier) was $-0.021 \pm 0.143$. With a true heritability of 0.0 and no correlated environments, neither estimate is biased, but the estimates from the family sets method were substantially more variable than those using the likelihood approach.

\section{DISCUSSION}

The conclusions from the two different statistical treatments of these data are consistent in spite of different statistical properties of the two approaches [27]. Estimates of the genetic component of blood pressure variability from both the likelihood analysis and family sets method are within the range of estimates presented in Table 1 for other studies. However, the family sets estimates were higher than the maximum likelihood estimates for both SBP and DBP in blacks and whites. There are a number of possible reasons for this difference. The family sets method may give biased estimates of heritability under certain conditions. Rodriquez et al. [28] performed a large Monte Carlo simulation study that compared the family sets approach to other conventional estimators, including the regression of the index on the midparent value and the index-sib correlation. With a true heritability of 1.0 , both the family sets estimator and the others were unbiased, but the standard deviation of the estimates using the family sets approach was more than twice that of the other two estimators. With a heritability of 0.32 and both dominance and correlated environments, only the estimator based on the regression of the index on the midparent value was unbiased. The standard deviation of the estimates from the family sets approach was again substantially larger than that of the other two estimators. In our single experiment, with a true heritability of 0.0 , estimates obtained using the family sets approach had a larger standard deviation than those obtained using the maximum likelihood method. Finally, any non-additive genetic factors and/or environmental factors that increase sib covariability compared to the covariability between the index and cousin will increase the estimate of heritability.

Reanalysis of the dala collected in Detroit supports the hypothesis that variability in genes among individuals is associated with blood pressure variability. The differences between blacks and whites in the strength of the association of genetic and environmental factors with variability in blood pressure are consistent with other reported racial differences. Studies of children have found racial differences in sympathomimetic and hormonal influences on blood pressure levels [29]. Studies of adults have found that while blacks and whites may ingest similar quantities of sodium, blacks ingest lower levels of dietary potassium [30]. In addition to diversity in diets, there is evidence for racial differences in sodium handling and renin response to sodium loading [31]. It is reasonable to conclude that differences in both environmental experiences and metabolic control of blood pressure between blacks and whites are probably reflected in the fit of different models to SBP and DBP variability in this study.

The reported strength of aggregation in spouses' blood pressure has varied among studies [19]. Annest et al. [5] and Krieger et al. [8] recently reported positive correlations while Morton et al. [6] found no significant positive correlation between spouses. Spouse similarity may be influenced by both length of cohabitation and assortative mating for phenotypes [23]. The results from our study suggest that environmental 
factors shared by spouses are associated with blood pressure variability in whites. In Detroit, the mean ages of indexes eligible for inclusion in the study and their spouses were similar for both blacks and whites in high stress areas. However, in the low stress areas, the white indexes and spouses were, on average, 4 years older than the black indexes and spouses. The statistics on separations and divorces from the 1965 survey of Detroit [9] suggest that marriage stability is equal for blacks and whites who reside in low stress areas but is substantially different for blacks and whites in high stress areas. For every separation or divorce in whites in the high stress areas there were approximately 4 separations or divorces in the blacks in high stress areas. While data were not collected, we can infer, based on the mean ages and indicators of marital stability, that on average the white spouses have lived together longer than the black spouses. Neither the shared stress area nor shared common environment between index and unrelated individual contributed to the aggregation of blood pressure levels. This confirms that the regression analyses successfully removed aggregation between individuals in a set due to similarity in race, age, sex, body size and residential stress area.

There are several explanations for the different conclusions reached in the reanalysis of these data compared to the conclusions reached in the original study [10]. Since the original study, a new estimator for the variance of $h^{2}$ has been derived by Chakraborty [26]. This new estimator reduces the standard error of $h^{2}$ approximately three-fold. With this new estimator, the original estimates for the heritability of SBP and DBP based on the unadjusted measurements for both blacks and whites with the index living in a low stress area [10] would be judged significantly different from zero. Instead, the null hypothesis was accepted [10].

The major departure in these analyses from the original analysis is the stratification of the data. In the analyses reported here, variability due to stress area was removed by regression techniques rather than used to stratify samples of family sets. A justification for this was based on the fact that only one-third of all sets had all members residing in a similar stress area. We also included in the same sample, family sets with index cases of different sexes. We did not exclude any family sets from our analyses. In the original study, 36 family sets where one or more individuals had extreme blood pressure levels were excluded. Our sample sizes were 229 sets for blacks and 232 sets for whites. Using the most recently derived estimator of variance which is given in equation 6 . any estimate greater than 0.31 would have been judged significantly different from zero in a sample of 230 sets. In the original study, Chakraborty et al. [10] excluded 36 sets and then stratified by stress area and by sex of the index case. Sample sizes ranged from 65 to 117 sets. Samples of these sizes would require estimates of $h^{2}$ of at least 0.5 or 0.6 (for 117 and 65 sets, respectively) to reject the null hypothesis that heritability was zero.

While simulation studies show that family sets estimators may give biased estimates under certain conditions [28], the design itself provides both genetic and environmental contrasts not always found in other designs such as twins or pairs of relatives $[32,33]$. The feasibility of assembling family sets has been demonstrated by several other researchers. Rodriquez [34] assembled all available index-sib-cousin trios from approximately 4000 children who were surveyed in Bogalusa, Louisiana [35]. Therefore, in a sample of school children collected prior to a decision to study familial aggregation, almost $1 / 4$ of the children were in the 327 sets assembled. Gilroy et al. [36] studied 43 family sets to estimate genetic control of glycolysis in human erythrocytes. Schork et al. [37] have been studying familial aggregation of reported alcohol use in 485 family sets of various sizes identified from the Tecumseh Study. With multiple methods of estimation available and the fcasibility of obtaining sets verified in several studies, this approach can provide an alternative sampling frame to supplement other approaches to the analysis of familial aggregation.

In reference to the Detroit Project, Feinleib and Garrison [38] have reported: "We do not have any cogent explanation for why this study should differ so strikingly from all other studies summarized previously." The reanalyses reported here of the data from Detroit using larger numbers of family sets lead to different conclusions than the original 
analyses of blood pressure variability, and the new conclusions are consistent with previously reported studies. This reanalysis affirms the usefulness of the family sets approach to understanding the relative roles of genetic and environmental variability in the distribution of quantitative traits.

Acknowledgements-We thank all the individuals who have been associated with the Detroit Project over the many years. We specifically want to thank Dr William J. Schull and Dr Ranajit Chakraborty for their many contributions. We thank Peter Roper and Thomas Berry for their assistance with the reanalyses. Dr Peter Smouse made several valuable suggestions on the manuscript. We are especially grateful to Dr Charles $F$. Sing for his stimulating discussions on family sets. Two anonymous reviewers substantially improved the paper.

\section{REFERENCES}

1. Pickering G: High Blood Pressure. New York: Grune and Stratton, pp. viii. 717. 1968

2. Tyroler HA: The Detroit project studies of blood pressure. A prologue and review of related studies and epidemiological issues. J Chron Dis 30: 613-624, 1977

3. Borhani NO. Feinleib M, Garrison RJ, Christian JC, Rosenman RH: Genetic variance in blood pressure. Acta Genet Med Gemellol (Roma) 25: 137-144. 1976

4. Ewell LW, Nance WE, Corey LA. Boughman JA : Blood pressure studies on monozygotic twins and their families. In Twin Research Clinical Studies. Nance W. (Ed.) New York: Alan R. Liss, pp. 29-38, 1978

5. Annest JL, Sing CF, Biron P, Mongeau J-G: Familial aggregation of blood pressure and weight in adoptive families. II. Estimation of the relative contributions of genetic and common environmental factors to blood pressure correlations between family members. Am J Epid 110: 492-503. 1979

6. Morton NE. Gulbrandsen CL, Rao DC, Rhoads GG, Kagan A: Determinants of blood pressure in Japanese-American families. Hum Genet 53: 261266.1980

7. Ward RH. Chin PG. Prior IAM: Genetic epidemiology of blood pressure in a migrating isolate: Prospectus. In Genetic Analysis of Common Diseases: Application to Predictive Factors in Coronary Disease. Sing CF, Skolnick M (Eds) New York: Alan R. Liss, pp. 675-709, 1979

8. Krieger H. Morton NE. Rao DC. Azevedo E: Familial determinants of blood pressure in Northern Brazil. Hum Genet 53: 415-418, 1980

9. Harburg E. Erfurt JC. Schull WJ, Schork MA. Colman R: Heredity, stress and blood pressure, a family set method. I. Study aims and sample flow. J Chron Dis 30: 625-648, 1977

10. Chakraborty R, Schull WJ, Harburg E, Schork MA, Roeper P: Heredity, stress and blood pressure, a family set method. V. Heritability estimates. J Chron Dis 30:683-700, 1977

11. Elston RC. Stewart J: A general model for the genetic analysis of pedigree data. Hum Hered $21: 523542$, 1971

12. Lange K. Westlake J. Spence MA: Extensions to pedigree analysis. III. Variance components by the scoring method. Ann Hum Genet (London) 39: 485-491, 1976

13. Spence MA, Westlake J, Lange K: Estimation of the variance components for dermal ridge count. Ann Hum Genet (London) 41: 111-115, 1977

14. Moll PP, Powsner R. Sing CF: Analysis of genetic and environmental sources of variation in serum cholesterol in Tecumseh. Michigan. V. Variance components estimates from pedigrees. Ann Hum Genet (London) 42: 343-354, 1979

15. Erfurt J, Harburg E, Rice R: A method for selection of census tract areas differing in ecological stress. Program for Urban Health Rescarch, 1970

16. Harburg E, Erfurt JC, Chape C, Hauenstein LS, Schull WJ, Schork MA: Socioecological stressor areas and black-white blood pressure. Detroit. J Chron Dis 26: 595-611, 1973

17. Metropolitan Life Insurance Company: Stat Bull Oct 1942, June 1943.

18. Harburg E, Erfurt JC, Schull WJ, Chape C: Heredity, stress and blood pressure, a family set method. II. Results of blood pressure measurement. J Chron Dis 30: 649-658, 1977

19. Schull WJ. Harburg E, Schork MA, Weener J, Chape C: Heredity, stress and blood pressure, a family set method. III. Family aggregation of hypertension. J Chron Dis 30: 659-670, 1977

20. Schork MA. Schull WJ, Harburg E, Roeper P, Chape C: Heredity, stress and blood pressure, a family set method. IV. Blood pressure adjustment techniques. J Chron Dis 30: 671-682, 1977

21. Schull WJ, Harburg E. Schork MA. Chakraborty R: Heredity, stress and blood pressure, a family set method. Epilogue. J Chron Dis 30: 701-704, 1977

22. Fisher RA: The correlation between relatives on the supposition of Mendelian inheritance. Trans R Soc Edinb 52: 399-433, 1918

23. Sackett DL: Studies of blood pressure in spouses. In Epidemiology and Control of Hypertension. Oglesby P (Ed.) Miami. Florida: Symposia Specialists, pp. 21-39, 1975

24. Lange K : Central limit theorems for pedigrees. J Math Biol 6: 59-66, 1978

25. Rao CR: Linear Statistical Inference and Its Applications, 2nd ed. New York. pp. xviii, 522. 1973

26. Chakraborty R: Appendix B. Variance of the estimator of $\mathrm{V}(\mathrm{A}) / \mathrm{V}(\mathrm{P})$ using family sets. In Genetic Analysis of Common Diseases: Applications to Predictive Factors in Coronary Disease. Sing CF. Skolnick M (Eds) New York: Alan R. Liss. pp. 341-342, 1979

27. Elandt-Johnson R: Probability Models and Statistical Methods in Genetics. New York; John Wiley, 1971

28. Rodriquez A, Chakraborty R, Schull WJ: Comparing the "Family Set" approach to estimate heritability with other conventional estimators: A Monte Carlo simulation. Hum Hered 30: 192-200, 1980

29. Voors AW, Berenson GS, Dalferes ER. Webber LS, Shuler SE: Racial differences in blood pressure control. Science 204: 1091-1904, 1979 
30. Grim CE, Luft FC, Miller JZ, Meneely HD, Battarbee HD, Hames CG. Dahl KK: Racial differences in Evans County, Georgia: Relationship to sodium and potassium intake and plasma renin activity. J Chron Dis 33: 87-94. 1980

31. Luft FC, Grim CE, Higgins JT Jr, Weinberger MH: Differences in response to sodium administration in nurmotensive white and black subjects. J Lab Clin Med 90: 555-562. 1977

32. Moll PP, Sing CF: Sampling strategies for the analysis of quantitative traits. In Genetic Analysis of Common Diseases: Applications to Predictive Factors in Coronary Disease. Sing CF, Skolnick M (Eds) New York: Alan R. Liss, pp. $307 \quad 342,1979$

33. Chakraborty R. Schull WJ: Fixed cluster designs in human genetic studies: interpretations and usefulness. In Genetic Analysis of Common Diseases: Applications to Predictive Factors in Coronary Disease. Sing CF. Skolnick M (Eds) New York: Alan R. Liss, pp. 343 361, 1979

34. Rodriquez A: A Monte Carlo simulation of the "Family Set" approach to estimate heritability. PhD thesis, University of Texas, 1976

35. Voors AW, Foster TA. Frerichs RE. Webber LS, Berenson GS: Studies of blood pressures in children ages 5-14 years in a biracial community: The Bogalusa Heart Study. Circulation 54:319, 1976

36. Gilroy TE, Brewer GJ, Sing CF: Genetic control of glycolysis in human erythrocytes. Genetics 94: $719-732,1980$

37. Schork MA, Harburg E, Moll PP, Burns TL, Ozgoren F: Familial and environmental effects of alcohol use. Program For Urhan Health Research, 1982.

38. Feinleib M, Garrison RJ: The contribution of family studies to the partitioning of population variation of blood pressure. In Genetic Analysis of Common Diseases: Applications to Predictive Factors in Coronary Disease. Sing CF, Skolnick M (Eds) New York: Alan R. Liss. pp. 653-673, 1979 